\title{
Stability formula and failure probability analysis of wave-dissipating blocks considering wave breaking
}

\author{
Hajime Mase • Tomohiro Yasuda - Maria T. Reis • \\ Harshinie Karunarathna • Jung-A Yang
}

Received: 15 May 2014 / Accepted: 1 September 2014 / Published online: 26 September 2014

(c) Springer International Publishing AG 2014

\begin{abstract}
The effects of wave steepness and wave breaking on the stability of wave-dissipating blocks placed on caisson breakwaters are examined by hydraulic experiments under conditions with and without wave breaking. It is confirmed that there is a clear dependence of the block stability on the wave steepness through the wave-breaking type, such as plunging and spilling breakers. The stability parameter in the spilling breaker case is larger than that in the plunging breaker case. For non-breaking wave conditions, there is no effect of the wave steepness. An empirical stability formula is proposed taking into account the effects of the wave steepness and the wave-breaking type. Finally, by using the stability formula, failure probabilities of the wave-dissipating blocks having a nominal diameter are evaluated by the first-order reliability method of the Level II reliability analysis.
\end{abstract}

Keywords Wave-dissipating block stability - Stability formula · Wave-breaking effect · Reliability analysis · Failure probability

H. Mase $(\bowtie) \cdot T$. Yasuda

Disaster Prevention Research Institute, Kyoto University, Gokasho, Uji, Kyoto 611-0011, Japan

e-mail: mase.hajime.5c@kyoto-u.ac.jp

M. T. Reis

Harbours and Maritime Structures Division, National Civil Engineering Laboratory, Avenida do Brasil 101, 1700-066 Lisbon, Portugal

H. Karunarathna

College of Engineering, Swansea University, Singleton Park, Swansea SA2 8PP, UK

J.-A. Yang

Graduate School of Engineering, Kyoto University,

Kyoto daigaku-Katsura, Kyoto 615-8530, Japan

\section{Introduction}

Composite breakwaters covered with wave-dissipating blocks, which reduce wave forces, reflect waves and reduce overtopping discharge, are widely used in Japan for coastal protection and in port construction. Because of recent increases to storminess of incoming wave conditions, a number of failures of composite breakwaters have been reported. Figure 1 shows a photo of damage to a composite breakwater (caisson sliding and block scattering) induced by waves that exceeded the design conditions at Susami Port, Wakayama Prefecture, Japan (Kim et al. 2006), and the original cross section of the damaged composite breakwater. In this context, accurate stability formulae are necessary to design resilient wave-dissipating blocks that are used to reduce wave damage to composite breakwaters.

Since rubble mound breakwaters are the most common type of breakwaters constructed around the world, there are many studies on the stability of rocks and various wavedissipating blocks used in them for wave dissipation (US Army Corps of Engineers 2002). One of the most important issues is the determination of armor block weight for which the non-dimensional stability number is usually used (e.g., Hudson 1958; Van der Meer 1987, 1988a). The stability number depends on the significant wave height, armor type, damage level and slope of the breakwater. Instead of using the significant wave height, Van der Meer (1988a) suggested using $H_{2} \%$ (wave height surpassed by the $2 \%$ highest waves) for depth-limited waves. Van Gent et al. (2003) carried out a series of stability tests of rubble mound breakwater and proposed van der Meer type formulae using wave height parameter $H_{2} \% / H_{\mathrm{s}}$, to take into account the upper limit of wave height distribution. Vidal et al. (2006) proposed using $H_{50}$ (the average of the 50 highest waves that reach the breakwater during its useful life) for better description of waves 
Fig. 1 Caisson sliding and block scattering on composite breakwaters of Susami Port, Wakayama Prefecture, Japan: a photo of damage; $\mathbf{b}$ cross section of the original composite breakwater a
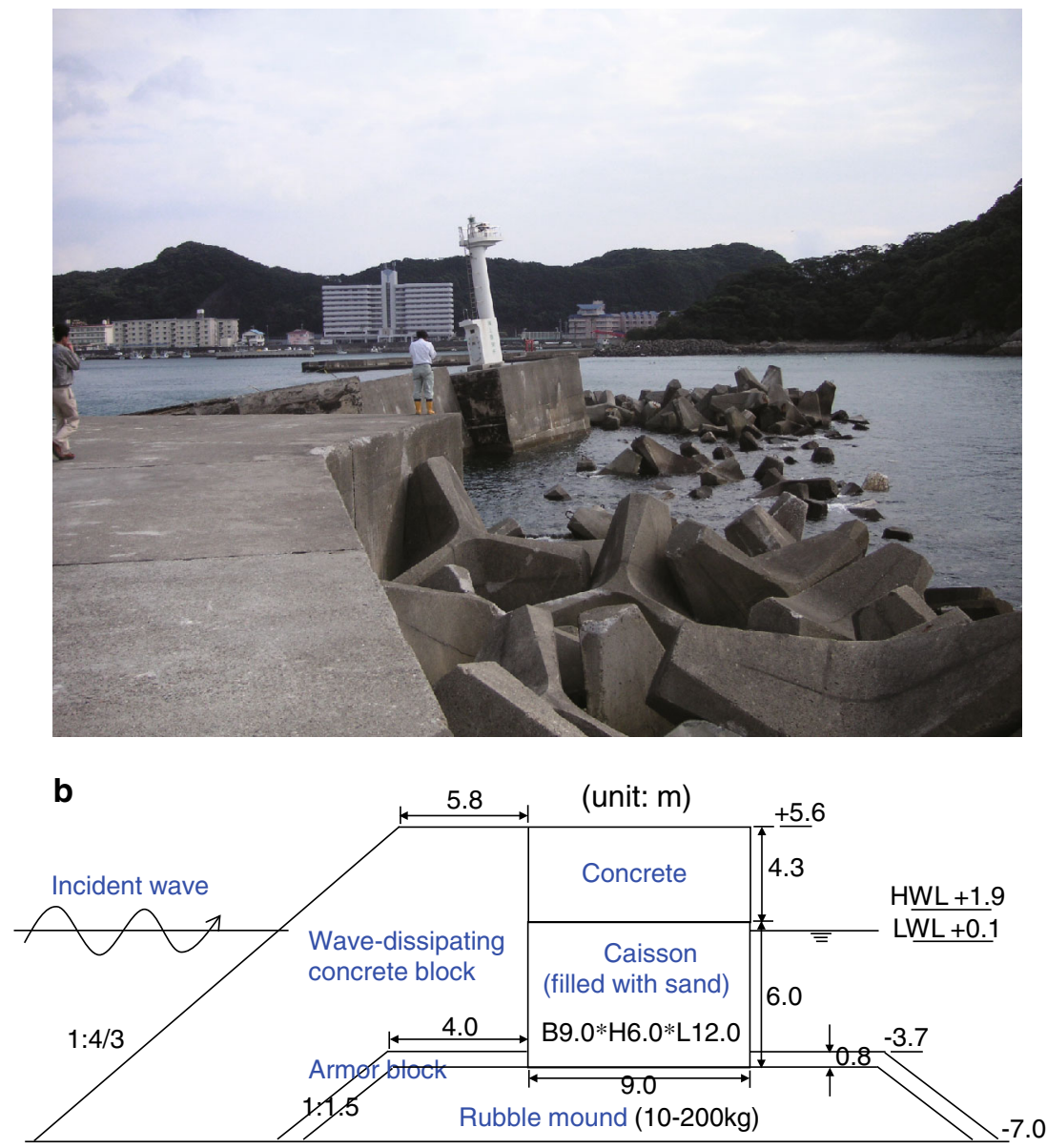

in the stability formulae in intermediate or shallow water. Etemad-Shahidi and Bali (2011) also employed the $H_{50}$ for their stability formulae of rubble mound breakwaters. The use of $\mathrm{H}_{2} \%$ and $\mathrm{H}_{50}$ is to include wave-breaking effects on the wave height distribution.

The present study takes into account the wave-breaking effects on the stability of wave-dissipating blocks, especially focusing on the effects of wave-breaking type on stability of blocks. Concerning the effect of wave steepness on concrete block stability, there are different results reported by different researchers; for example, Van der Meer (1988b) reported that the larger the wave steepness, the lesser is the stability for mound breakwaters. On the other hand, Kashima et al. (1993) reported an opposite tendency for composite breakwaters. Hanzawa et al. (1996) reported that the influence of wave steepness on the block stability parameter is negligible. These differences have not been fully explained until now.

In this study, three series of hydraulic experiments were carried out to examine the effects of the wave steepness and the wave-breaking type on the stability of blocks that cover the caisson of a composite breakwater. Based on experimen- tal results, an empirical stability formula is proposed by taking into account the effects of the wave steepness and the wave-breaking type. By using the proposed formula, failure probabilities of wave-dissipating blocks are determined by a Level II method of reliability analysis, known as the first-order reliability method (FORM) (Reis 1998), in which the significance of the contribution of the uncertainty of random variables (such as wave heights, wave steepness, error of stability formula and so on) to the variance of the result is investigated.

Section 2 in this paper gives a description of the stability formulae for wave-dissipating blocks and armor layer. In Sect. 3, new hydraulic experiments on block stability are described. Section 4 summarizes the experimental results for two series of experiments, and Sect. 5 proposes a stability formula considering wave breaking. The stability formula is then checked against the third series of experimental results. Section 6 describes the reliability analysis based on the stability formula developed in Sect. 5 and investigates the influence of the uncertainty of input variables on the variance. Section 7 concludes the study. 


\section{Stability formulae of blocks and armor layer, and the effects of wave breaking}

Hanzawa et al. (1996) proposed the following empirical formula for the stability parameter of tetrapods covering a caisson over a sloping sea bottom:

$N_{S}=\frac{H_{1 / 3}}{\Delta D_{n}}=C_{H}\left\{a\left(N_{o d} / N^{0.5}\right)^{c}+b\right\}$

where $H_{1 / 3}$ is the significant wave height in front of the breakwater, $\Delta$ is given by $\left(S_{r}-1\right)\left(S_{r}=\rho_{\mathrm{s}} / \rho_{\mathrm{W}}: \rho_{\mathrm{s}}\right.$ and $\rho_{\mathrm{w}}$ are the mass density of concrete and water, respectively), $D_{n}$ is the equivalent cube length (i.e., the length of a cube with the same volume as a tetrapod), $N_{o d}$ is the number of units displaced from the armor layer within a strip width of one cube length $D_{n}, N$ is the number of waves, and $a$ and $b$ are empirical coefficients to be determined by the experiments. Equation (1) was applied to the experiments of model tests under the conditions: (1) irregular head-on waves, (2) water depth from 0.25 to $0.50 \mathrm{~cm}$, (3) $1: 1.5$ slope, (4) foreshore slope from 1:15 to $1: 100$, (5) mass of tetrapods from 90 to $700 \mathrm{~g}$, (6) significant wave heights from 8.0 to $25.9 \mathrm{~cm}$, (7) significant wave periods from 1.74 to $2.5 \mathrm{~s}$, (8) surf similarity parameter from 0.013 to 0.04 .

The value of $c$ is fixed as 0.2 . For tetrapods with a stability coefficient $K_{D}$ of 8.3 with armor slope $\cot \alpha=4 / 3$, $a=2.32$ and $b=1.33$ were obtained by Hanzawa et al. (1996) and Takahashi et al. (1998). Hanzawa et al. (1996) considered that the required block weight might be overestimated by Van der Meer (1987) formula when wave breaking occurs. As a result, they introduced the coefficient $C_{H}$ representing the wave-breaking effect in the stability formula of wave-dissipating blocks (Eq. 1); $C_{H}=1.0$ for non-breaking wave conditions and $C_{H}=1.4\left(H_{1 / 20} / H_{1 / 3}\right)$ for breaking wave conditions, where $H_{1 / 20}$ is the average of the highest one-twentieth of the waves in front of the breakwater. In the surf zone, the tail area of the wave height distribution and the maximum wave height decrease compared to those in the shoaling zone. Therefore, Van der Meer (1988a), Hanzawa et al. (1996) and Takahashi et al. (1998) considered that the stability of blocks in the case of breaking wave conditions over a sloping beach is higher than the stability in non-breaking wave conditions.

It is certain that blocks are stable when high waves are not present. However, fluid motion of breaking waves is generally more intense than that of non-breaking waves for the same wave height. According to the Shore Protection Manual (SPM) (1984), the value of $K_{D}$ for rocks on two-layer armored non-overtopped slopes based on regular wave tests is set as 1.2 for breaking conditions and 2.4 for non-breaking conditions. This means that the block stability reduces when subjected to breaking waves. The 'Armor Stones and Blocks' section of Technical Standards and Commentaries for Port and Harbour Facilities in Japan (2007) suggests considering strong wave forces acting against blocks of some shapes when the sea bottom slope is steep, plunging breaker occurs and blocks often become unstable by wave breaking when the depth of the mound is shallow.

For instance, though the value of $H_{1 / 3}$ is the same, the force acting on blocks by breaking waves might be larger than that by non-breaking waves. Hanzawa et al. (1996) analyzed their experimental data and found that when the wave steepness is between 0.02 and 0.04 , the influence of the wave steepness on the block stability parameter is negligible. As a result, neither the wave steepness nor the surf similarity parameter is included in the stability formula. However, it should be noted that there is a large variation in their experimental results.

It is considered that the wave-breaking type and the wave steepness are related to the block stability through the wave height distribution, wave energy dissipation and fluid motion. Therefore, investigation of the effects of the wave-breaking type and the wave steepness on the block stability is still required to develop a precise stability formula for wavedissipating blocks subjected to extreme storm wave conditions.

\section{Hydraulic experiments}

A wave flume of $50 \mathrm{~m}$ length, $1.0 \mathrm{~m}$ width and $1.5 \mathrm{~m}$ depth was used to conduct hydraulic experiments. The flume is fixed with an absorption-type random wave maker. The energy spectrum of random waves is determined by the Bretschneider-Mitsuyasu type of spectrum. Table 1 shows the wave conditions used in the experiments, where the wave height, period, length and steepness are shown against the case identification (Case ID).

Three series of experiments were carried out to examine the effects of the wave steepness and the wave-breaker type on the block stability; the first series of experiments was done on a 1/30 sloping sea bottom; the second one on a constant uniform water depth; and the third one on a 1/15 sloping sea bottom.

The two breakwater cross sections are shown in Fig. 2; Fig. 2a shows the 1/30 sloping sea bottom case, and Fig. 2b shows the flat bed case with $1 / 5$ slope in front of the flat bed. In both cases, the slope of the randomly placed wavedissipating blocks was fixed at $1 / 1.5$. The model scale is $1 / 50$ according to Froude's law. The third series of experiments is similar to Fig. 2a, but with a 1/15 sloping sea bottom in front of the breakwater. Wave gages were set at 10.0 and 11.0 $\mathrm{m}$ from the wave paddle, and at 2.0, 3.0 and $3.5 \mathrm{~m}$ from the caisson of the breakwater. 
Table 1 Wave conditions used in hydraulic experiments

Columns \#1, 3, 6: wave heights at constant depth, deep-water, front of structure (unit: $\mathrm{m}$ ) Column \#2: wave period (s) at constant depth; Column \#5: deep-water wave steepness

\begin{tabular}{|c|c|c|c|c|c|c|c|}
\hline Case ID & $\left(H_{1 / 3}\right)_{i}$ & $\left(T_{1 / 3}\right)_{i}$ & $\left(H_{1 / 3}\right)_{0}$ & $L_{0}$ & $\left(H_{1 / 3}\right)_{0} / L_{0}$ & $H_{1 / 3}$ & $L_{1 / 3}$ \\
\hline H10HL4S1/30-1 & 0.12 & 1.30 & 0.13 & 2.64 & 0.048 & 0.10 & 1.68 \\
\hline H10HL4S1/30-2 & 0.12 & 1.30 & 0.13 & 2.64 & 0.048 & 0.10 & 1.68 \\
\hline H10HL2S1/30-1 & 0.10 & 2.00 & 0.11 & 6.24 & 0.018 & 0.10 & 2.71 \\
\hline H10HL2S1/30-2 & 0.10 & 2.00 & 0.12 & 6.24 & 0.018 & 0.10 & 2.71 \\
\hline H15HL4S1/30-1 & 0.17 & 1.70 & 0.19 & 4.51 & 0.042 & 0.15 & 2.27 \\
\hline H15HL4S1/30-2 & 0.18 & 1.70 & 0.20 & 4.51 & 0.044 & 0.15 & 2.27 \\
\hline H15HL2S1/30-1 & 0.16 & 2.90 & 0.16 & 13.12 & 0.012 & 0.15 & 4.00 \\
\hline H15HL2S1/30-2 & 0.16 & 2.90 & 0.16 & 13.12 & 0.012 & 0.16 & 4.00 \\
\hline H20HL4S1/30-1 & 0.24 & 2.00 & 0.27 & 6.24 & 0.042 & 0.20 & 2.71 \\
\hline H20HL4S1/30-2 & 0.28 & 2.00 & 0.31 & 6.24 & 0.050 & 0.20 & 2.71 \\
\hline H10HL4S1/ $\infty$ & 0.10 & 1.30 & 0.11 & 2.64 & 0.041 & 0.09 & 2.54 \\
\hline 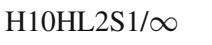 & 0.10 & 2.00 & 0.11 & 2.64 & 0.042 & 0.09 & 4.85 \\
\hline H15HL4S1/ $\infty$ & 0.16 & 1.70 & 0.17 & 6.24 & 0.027 & 0.13 & 3.88 \\
\hline H15HL3S1/ $\infty$ & 0.15 & 2.00 & 0.14 & 6.24 & 0.023 & 0.13 & 4.85 \\
\hline 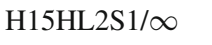 & 0.14 & 2.90 & 0.14 & 4.51 & 0.031 & 0.13 & 7.61 \\
\hline H $20 \mathrm{HL} 4 \mathrm{~S} 1 / \infty$ & 0.23 & 2.00 & 0.25 & 6.24 & 0.040 & 0.18 & 4.85 \\
\hline H15HL4S1/15 & 0.20 & 1.70 & 0.22 & 4.51 & 0.049 & 0.18 & 2.27 \\
\hline H15HL3S1/15 & 0.16 & 2.00 & 0.18 & 6.24 & 0.029 & 0.15 & 2.71 \\
\hline
\end{tabular}

Fig. 2 Cross section of experimental setup: a first series of experiments; $\mathbf{b}$ second series of experiments

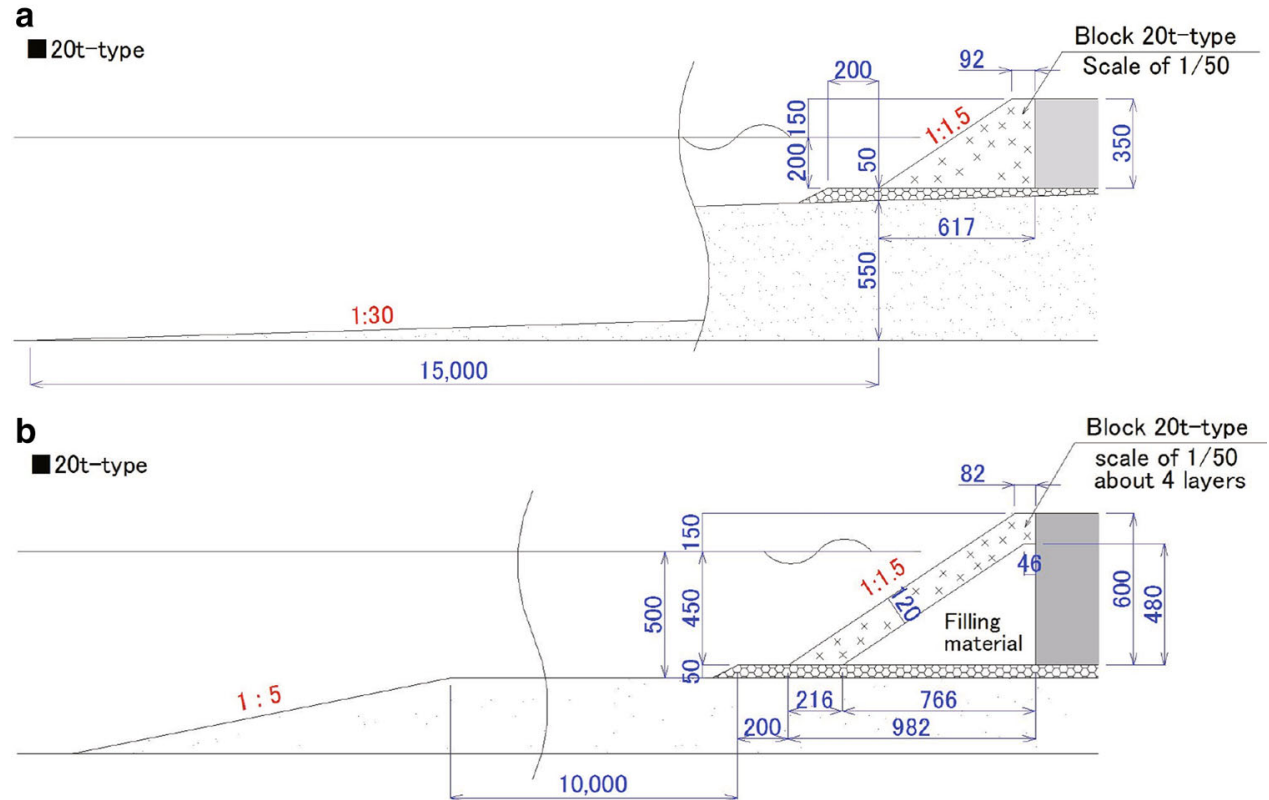

In the first series of experiments, wave breaking occurs on the sloping sea bottom and breaking waves attack the breakwater. In the second series of experiments, wave breaking did not occur as a result of the large water depth in front of the breakwater.

Wave-dissipating blocks with radiating shape were used in the experiments. As shown in Fig. 3, they have a dimple in the center, to improve interlocking and friction effects.
Blocks with two different weights were tested: 16 and $20 \mathrm{t}$ in the prototype scale. The number of blocks displaced from the armor layer was counted after 500, 1,000 and 2,000 waves. Then, the number of displayed blocks $N_{o d}$ within a strip width of one cube length, defined as 'damage parameter', was determined. In this process, the blocks that were half moved and that were rotated by $45^{\circ}$ or more were also counted as 'displaced' blocks. 
Fig. 3 Wave-dissipating blocks used in the experiments

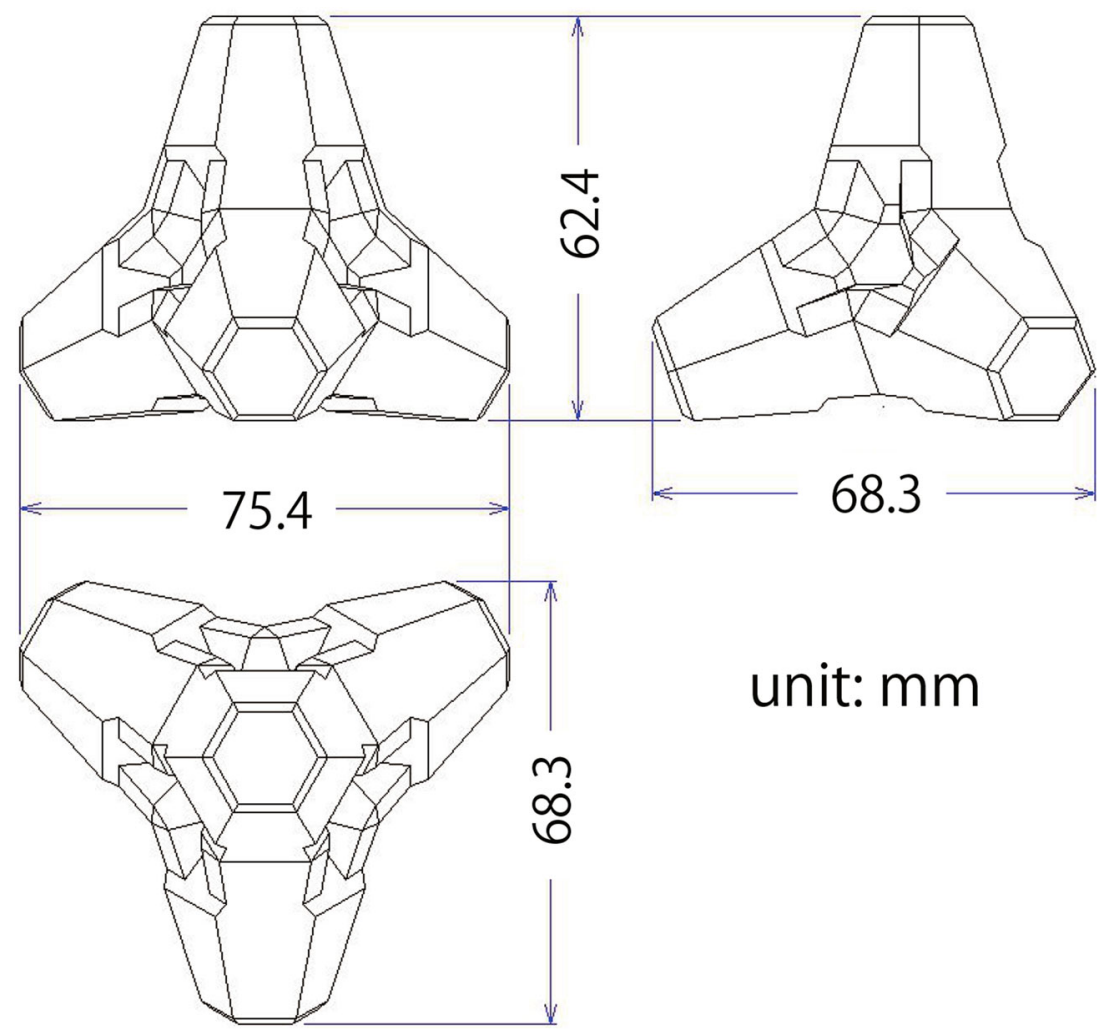

\section{Experimental results}

\subsection{First series of sloping sea bottom case}

The stability of wave-dissipating blocks of the breakwater placed on a 1/30 sloping sea bottom is first discussed based on Eq. (1). The relationship between the damage rate (damage parameter divided by $N^{0.5}$ ) and the stability parameter is shown in Fig. 4. The dashed line is the regression line formulated by Hanzawa et al. (1996) and Takahashi et al. (1998). Additionally, two fitted lines for the new experimental results (dotted and solid lines), determined by the least-squares method, are also displayed: the dotted line was determined by fixing $c$ as 0.2 and then determining $a$ and $b$; the solid line was determined by taking all $a, b$ and $c$ as unknown values.

When the trend lines determined by the least-squares method are plotted using the logarithmic axes, the results seem to be well arranged. However, when the results are drawn with linear axes, as shown in Fig. 4, it can be seen that the experimental results are separated into two groups. To investigate this further, the results were separated according to the deep-water incident wave steepness. In Fig. 5, the results corresponding to deep-water incident wave steepness less than 0.02 and more than 0.04 are shown separately. It is clear in this figure that the deep-water incident wave steepness is a significant determining parameter for the block stability.

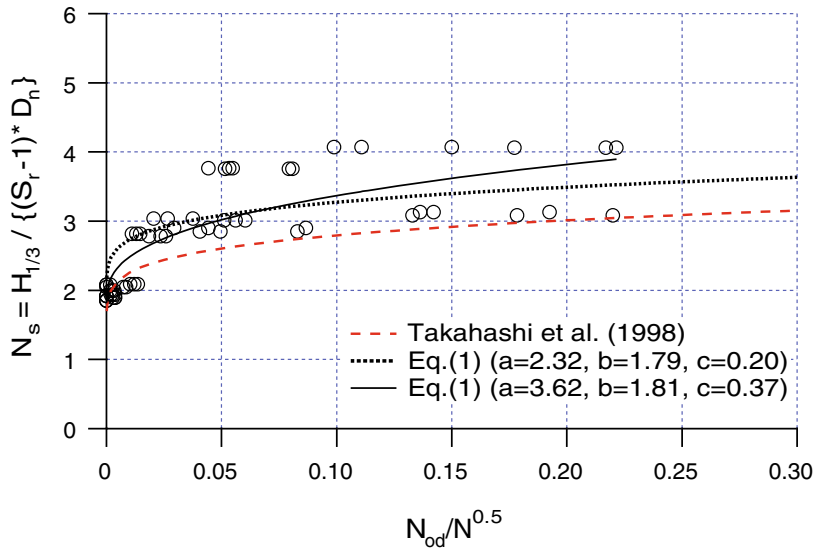

Fig. 4 Relation between damage rate and stability parameter together with regression lines

According to the wave-breaker classification of Hayami (1958), the wave-breaker type is a function of the incident wave steepness. As a result, it can be concluded that the influence of the wave-breaker type on the block stability cannot be disregarded.

\subsection{Second series of flat sea bottom case}

The stability parameter of wave-dissipating blocks of the breakwater placed on a flat sea bottom with no wave break- 


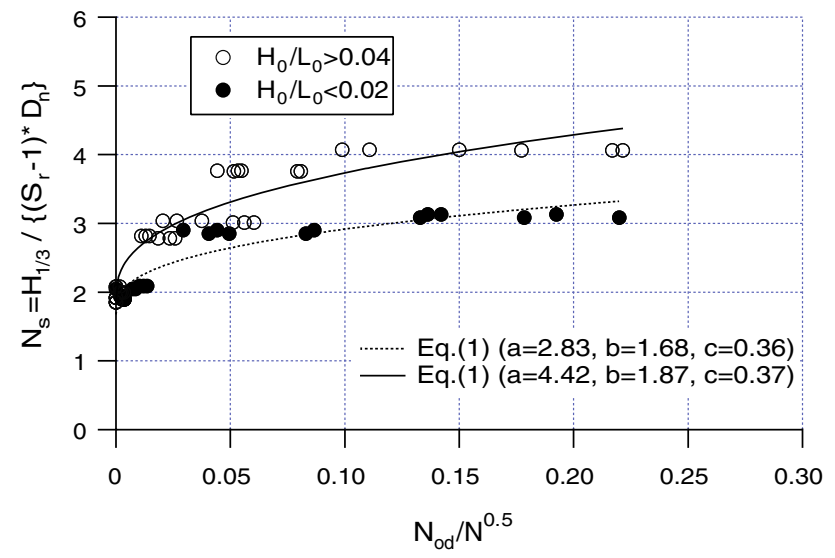

Fig. 5 Relation between damage rate and stability parameter when classified by wave steepness

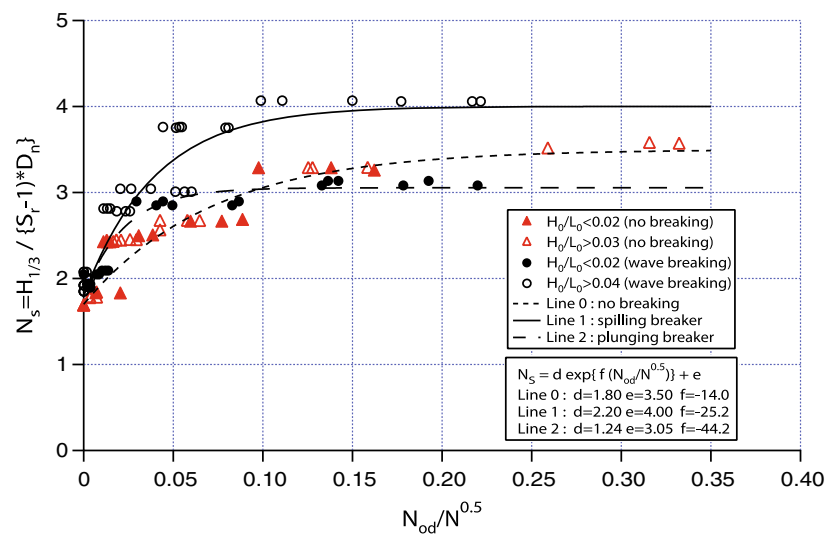

Fig. 6 Relation between damage rate and stability parameter for the condition of non-breaking (triangular symbols) and breaking (circles) waves

ing was investigated and the results are summarized in Fig. 6. The results were separated by two thresholds of deep-water incident wave steepness: $H_{0} / L_{0}<0.02$ and $H_{0} / L_{0}>0.03$. The results of wave-breaking cases were also included in this figure for clarity. The effect of the deep-water incident wave steepness on the stability parameter cannot be seen in the flat sea bottom case. Since an exponential function seems to be more suitable as the regression curve than a power function, an exponential function was used and the three fitted curves were determined by the least-squares method as shown in Fig. 6. The fitted exponential function is given by

$N_{S}=\frac{H_{1 / 3}}{\Delta D_{n}}=d \exp \left\{f\left(N_{o d} / N^{0.5}\right)\right\}+e$

where the coefficients $d, e$ and $f$ are non-dimensional fitting parameters. A direct comparison between the predicted stability parameters by the stability formula of Eq. (2) and the experimental results are shown in Fig. 7. The corresponding correlation coefficient is 0.95 .

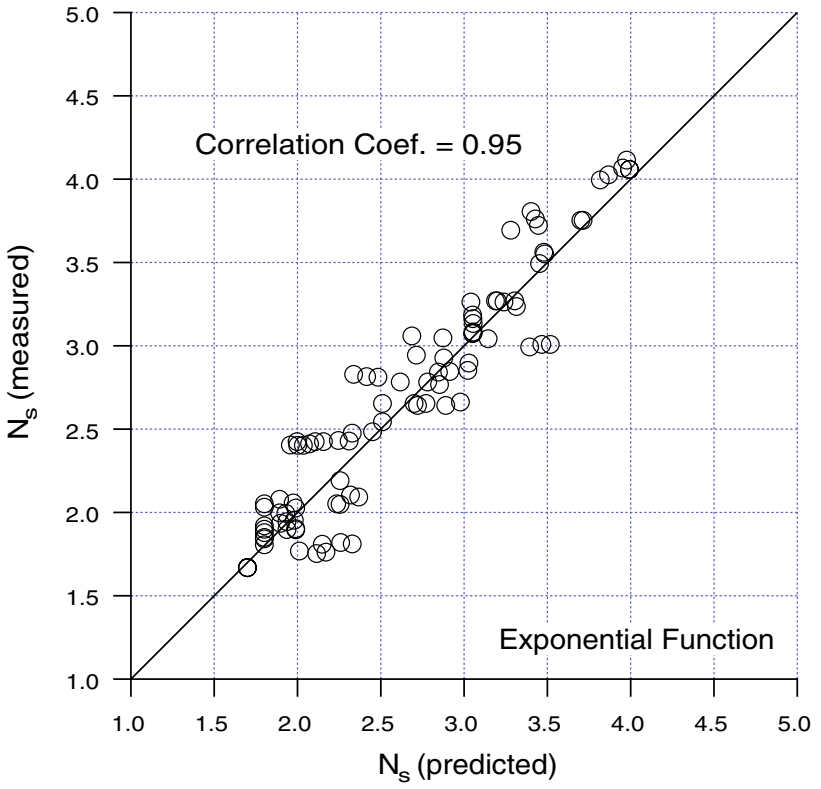

Fig. 7 Direct comparison of stability parameters obtained from the first and the second series of experiments and from predictions by the stability formula using an exponential function

In Sect. 5, the third series of experimental results mentioned in Sect. 1 is used to check the stability formula derived above. The results are also presented and discussed.

\section{Stability formula considering wave breaking}

It is assumed that the stability parameter of wave-dissipating blocks in breakwaters depends on whether wave breaking occurs or not. In the case of breaking incident waves, the effect of wave breaking can be included into the stability formula by introducing the sea bottom slope and the deep-water wave steepness. The values of the wave steepness for spilling and plunging breakers in the experiments were averaged first. The averaged wave steepness is treated as the representative value for spilling and plunging breaker conditions. It is also assumed that the stability parameter varies linearly with the wave steepness on the same bottom slope. The threshold between spilling and plunging breakers is shown in Fig. 8. In this figure, the stability parameter on the straight lines $S$ and $P$ is assumed to be the same as the stability parameter obtained for the case of $1 / 30$ sloping sea bottom.

The following method is different from the previous studies. Additional studies to verify the present method for other types of breakwaters are issues in the future. The idea of the proposed stability formulae are as follows: the averaged wave steepnesses for plunging and spilling wave cases in the first series of experiments are plotted in Fig. 8 as solid circles, shown as points $P_{1}$ and $P_{2}$, respectively. The wave steepness 


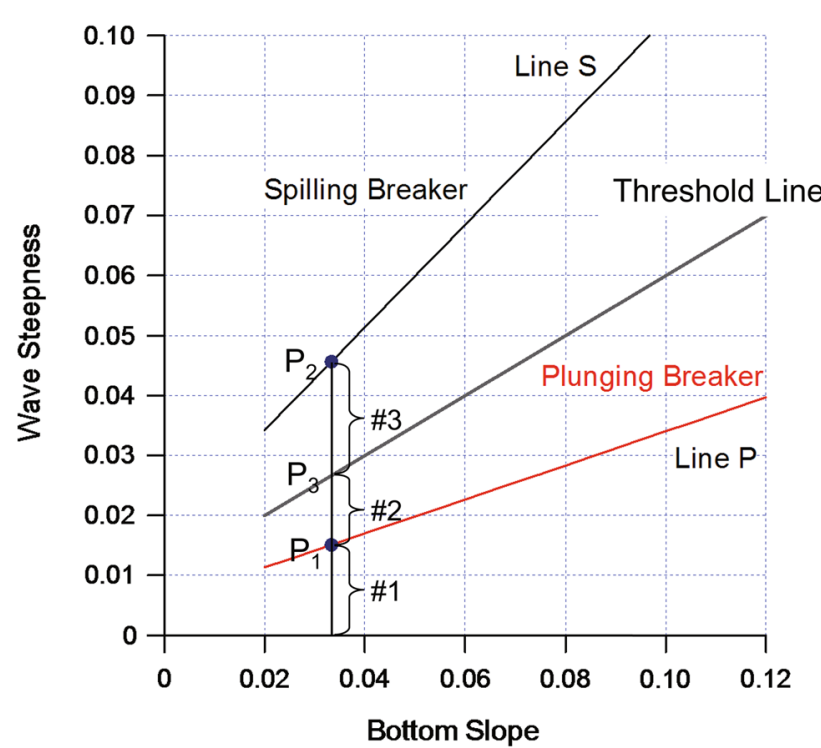

Fig. 8 Formulation method of stability formula to consider wavebreaking effect (breaker type)

threshold for the $1 / 30$ sea bottom slope is shown as $P_{3}$. Then, the ratios of \#1: \#2 and \#2: \#3 (Fig. 8) are used to construct the two straight lines, Line $\mathrm{S}$ and Line $\mathrm{P}$. Lines $\mathrm{S}$ and $\mathrm{P}$ have the following empirical equations:

$$
\begin{aligned}
& H_{0} / L_{0}=0.86 \tan \beta+0.017 \\
& H_{0} / L_{0}=0.28 \tan \beta+0.006
\end{aligned}
$$

in which $H_{0} / L_{0}$ is the deep-water incident wave steepness and $\tan \beta$ is the sea bottom slope. On Line $\mathrm{S}$ and on Line $\mathrm{P}$, the stability parameter $N_{S}$ is presumed to be the same; i.e. $N_{S}$ on Line $\mathrm{S}$ is given by Line 1 (spilling breaker case) in Fig. 6, and $N_{S}$ on Line $\mathrm{P}$ is given by Line 2 (plunging breaker case) in Fig. 6. In addition, it is assumed that the stability in the region between Line $S$ and Line $P$ varies linearly with the wave steepness, and the coefficients $d, e$ and $f$ in Eq. (2) are found as follows:

$d=\frac{H_{0} / L_{0}+0.456 \tan \beta+0.009}{0.597 \tan \beta+0.012}$

$e=\frac{H_{0} / L_{0}+1.560 \tan \beta+0.031}{0.603 \tan \beta+0.012}$

$f=\frac{H_{0} / L_{0}-1.620 \tan \beta-0.032}{0.030 \tan \beta+0.001}$

By employing Eqs. (5)-(7), the stability formula can be represented for all wave conditions of non-breaking and breaking for the radiation shape blocks considered in this study. This method can be extended to other types of blocks when required to determine wave-breaking effects on block stability.

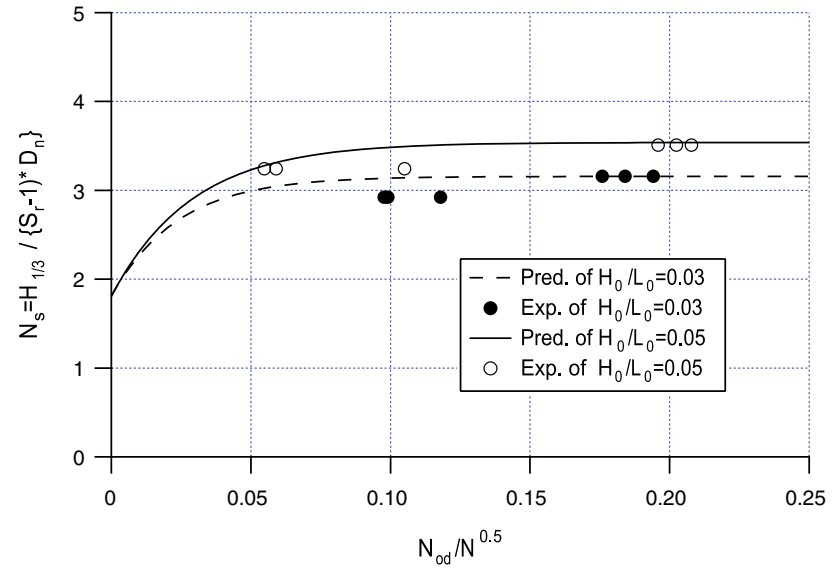

Fig. 9 Comparison between the results of the third series of experiments and predictions of those by the stability formula

The applicable range of the ratio of water depth in front of the breakwater to deep-water wave height, $h / H_{0}$ for the breaking wave conditions is $1.5<h / H_{0}<2.5$. In a deeper location, where $h / H_{0}>2.5$, the stability formula for nonbreaking wave conditions should be used. In a very shallow water region, the equation of non-breaking wave conditions can be used, since there are bore waves and the impact forces do not exist. Therefore, it should be noted that the proposed equation is consistent with previous studies, but cover more complex and extended conditions.

The stability formulae proposed in the present study can be summarized as follows:

No breaking case:

$N_{S}=\frac{H_{1 / 3}}{\Delta D_{n}}=-1.80 \exp \left\{-14.0\left(N_{o d} / N^{0.5}\right)\right\}+3.50$

Breaking case $\left(1.5<h / H_{0}<2.5\right)$ :

$N_{S}=\frac{H_{1 / 3}}{\Delta D_{n}}=d \exp \left\{f\left(N_{o d} / N^{0.5}\right)\right\}+e$

$d=\frac{H_{0} / L_{0}+0.456 \tan \beta+0.009}{0.597 \tan \beta+0.012}$

$e=\frac{H_{0} / L_{0}+1.560 \tan \beta+0.031}{0.603 \tan \beta+0.012}$

$f=\frac{H_{0} / L_{0}-1.620 \tan \beta-0.032}{0.030 \tan \beta+0.001}$

The results of the third series of experiments were used to check the validity of the proposed formula. Figure 9 shows the stability parameter against damage rate for the case of $1 / 15$ sloping sea bottom. It can be seen that the proposed formula reproduced experimental results for the $1 / 15$ sea bottom case very encouragingly. 


\section{Reliablity analysis}

Probabilistic methods provide a powerful framework for the design of coastal defenses. In this work, the computer program PARASODE-BALI (Probabilistic Assessment of Risks Associated with Seawall Overtopping, Dune Erosion and Breakwater Armour Layer Instability) has been used, which is an extended version of PARASODE (Reis 1998) and uses the Level II first-order reliability method (FORM). As the name suggests, the program concentrates on three failure mechanisms, but the majority of the code is generic and can be applied with minor adjustments to other types of failure. An application of PARASODE-BALI for probabilistic wave overtopping evaluation can be found in Reis et al. (2006).

The failure function corresponding to Eq. (9) can be rewritten as

$Z=N_{o d}-\frac{N^{0.5}}{f} \log \left\{\frac{H_{s}}{\operatorname{Err}\left(S_{r}-1\right) D_{n} d}-\frac{e}{d}\right\}$,

in which the error parameter, Err, between the predictions $P$ and the true values $T$ is considered to introduce the scatter of experimental data. Err is a measure of the scatter about the line of perfect agreement, as shown in Fig. 7, between the predicted and measured values of $N_{S}$. Since Err $=P / T$, the mean value of Err is expected to be about 1 . Since it is rather difficult to define the statistical distribution of Err, the beta distribution is used in the present study by some considerations as follows: (1) bearing in mind that the mean value of Err is about 1, the lower and upper limits suggest some asymmetry about the mean; (2) the domain of its distribution is not expected to include zero or negative values; (3) therefore, distributions such as the normal, Gumbel, gamma and Rayleigh can be discarded; (4) distributions such as the lognormal, Weibull and beta provide asymmetry; (5) the beta distribution is $x_{1} \leq$ Err $\leq x_{2}$. Although the beta distribution with lower and upper limits of 0.8 and 1.2 is used here, another choice is possible after a detailed analysis of errors for physical model tests.

$N_{o d}$ is related to damage rate $D(\%)$ as $N_{o d}=(0.2 \sim$ 0.3) $D$ (Takahashi et al. 1998). When $D=1 \%, N_{o d}=0.3$. $N_{o d}$ is used as a design value of armor block stability in Japan on some occasions. For the accumulation of block displacements by storm successions, $N_{o d}$ can be easily applied to estimate the cumulative number of displaced armor blocks (Takahashi et al. 1998). Therefore, in this study, $N_{o d}$ was used in an explicit form, and in a form of difference between the designed $N_{o d}$ and estimated $N_{o d}$ by Eq. (2). The value of $N_{o d}$ is chosen as 0.3 and 1.0 in the present analysis.

Table 2 shows the variables and their distribution functions used in the present reliability analysis, as well as the following distribution parameters: mean value, $\mu$, standard deviation, $\sigma$, and lower and upper limits for the beta function,
Table 2 Characteristics of the random variables used in the present reliability analysis

\begin{tabular}{lllll}
\hline Variables & Distribution & $\mu$ & $\sigma$ & $x_{1}, x_{2}$ \\
\hline $\begin{array}{l}\text { Significant } \\
\text { wave height } \\
\text { Beach slope }\end{array}$ & Gumbel & 7.45 & 1.0 & \\
& Normal & 0.0333 & $\begin{array}{c}0.0001 \text { assumed } \\
\text { as almost } \\
\text { constant }\end{array}$ \\
Wave steepness & Normal & 0.02 & 0.00102 & \\
& & 0.04 & 0.00204 & \\
$\begin{array}{c}\text { Number of } \\
\text { waves }\end{array}$ & Beta & 1,000 & 150 & $\begin{array}{l}x_{1}=400 \\
x_{2}=3,000 \\
x_{1}=0.8 \\
x_{2}=1.2\end{array}$ \\
\hline
\end{tabular}
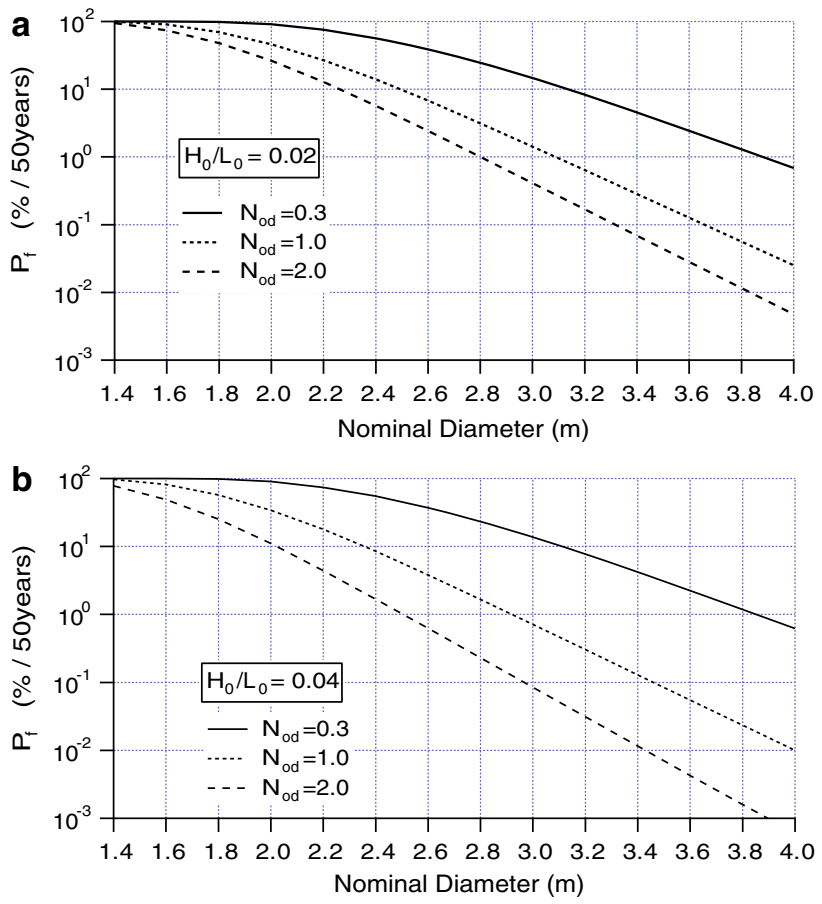

Fig. 10 Failure probability versus the nominal block diameter by changing allowable damage parameter. a $H_{0} / L_{0}=0.02$; b $H_{0} / L_{0}=$ 0.04

$x_{1}$ and $x_{2}$. The Gumbel distribution for annual maximum wave heights was used for evaluation of failure probability per 50 years since Mase et al. (2000) reported from the numerical experiments that the distribution of error between the true value of probabilistic return wave height and the estimated one from the fitted generalized Pareto distribution can be represented by the Gumbel distribution. The beach slope is usually constant; here, the slope is assumed to be almost constant, but randomly distributed a little. For the randomness of wave number and error of formulas, the beta distribution was applied to have upper and lower limits as shown in Table 2. These settings are usually determined according the actual 

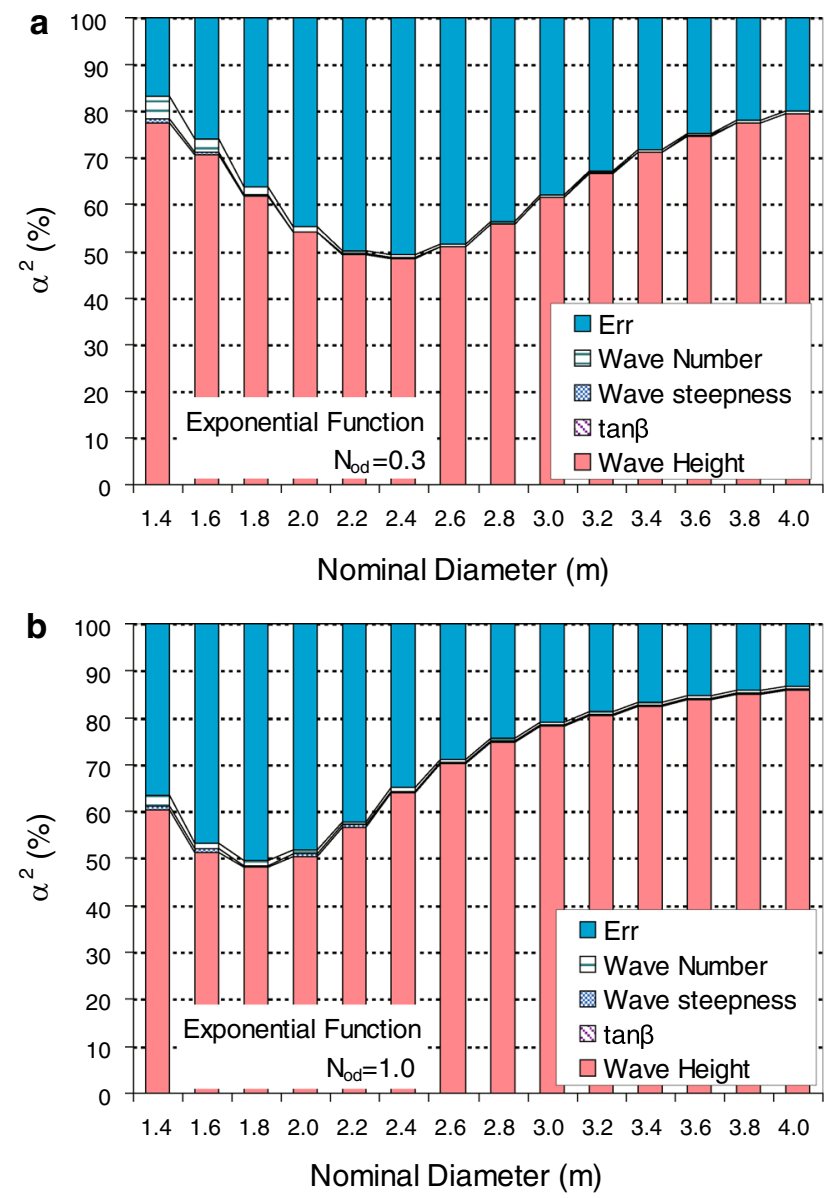

Fig. 11 Contribution of each random variable to the failure probability a $N_{o d}=0.3 ; \mathbf{b} N_{o d}=1.0$

observations; however, here, the settings are used as a trial and easily changed in PARASODE (1998). The estimated failure probabilities are shown in Fig. 10, where the horizontal axis is the nominal diameter, which is the equivalent cube length with the same volume as the block used in this study, by changing the allowable damage parameter, $N_{o d}$, for the representative wave steepnesses of 0.02 and 0.04 . As expected, the failure probability becomes smaller for larger nominal diameters and larger damage parameters.

Figure 11 shows the so-called sensitivity factors, which represent the contribution of each random variable to the variance of the failure probability. For a given allowable damage parameter, the tendency of relative magnitude of random variables (or uncertainty) differs. The wave height distribution and the error distribution have large contributions to the variance of the failure probability. Probabilistic methods can be used to determine which random external factors are important for a given situation. When such variables are identified, attention should be paid to the definition of their statistical characteristics.

\section{Conclusions}

The present study examined the stability of wave-dissipating blocks by hydraulic model experiments and proposed a new stability formula considering wave-breaking effects through the wave steepness and the sea bottom slope. The main results may be summarized as follows.

1. When wave breaking occurs on a sloping bottom and breaking waves attack the breakwater covered with blocks, the influence of the deep-water wave steepness on block stability is significant. This influence results from the different wave-breaking types through the wave steepness and the bottom slope.

2. A new stability formula was derived using an exponential function to include the effect of the wave steepness, which represents the wave-breaking type.

3. The proposed stability formula gave good predictions for a series of experiments that was not used for its development.

4. Probabilistic methods provide a powerful framework for the design of the wave-dissipating block size. The firstorder reliability method can be used to obtain failure probabilities and to analyze which are the most important variables that affect the variance of the probability of failure of the block stability of caisson breakwaters.

Acknowledgments The authors should like to express our thanks to Dr. H. Matsushita, Nikken Kogaku Co.Ltd. for his assistance in experiments.

\section{References}

Etemad-Shahidi A, Bali M (2011) Stability of rubble-mound breakwater using $H_{50}$ wave height parameter. Coast Eng 59(1):38-45

Hanzawa M, Sato H, Takahashi S, Shimosako K, Takayama T, Tanimoto K (1996) New stability formula for wave-dissipating concrete blocks covering horizontally composite breakwaters. In: Proceedings of 25th international conference on coastal engineering, ASCE, vol 2, pp 1665-1678

Hayami S (1958) Type of breakers, wave steepness and beach slope. Coast Eng Jpn 1:21-23

Hudson RY (1958) Design of quarry stone cover layer for rubble mound breakwaters. Research report No. 2-2, Waterways Experimental Station, Coastal Engineering Research Center, Vicksburg

Kashima R, Sakakiyama T, Shimizu T, Sekimoto T, Kunisu H, Kyotani O (1993) Estimation formula of wave-dissipating blocks against random waves. Annu J Coast Eng 40:795-799 (in Japanese)

Kim T-M, Yasuda T, Mase H, Takayama T (2006) Computational reproduction of caisson sliding failure due to Typhoon Tokage. In: Proceedings 30th international conference on coastal engineering, ASCE, pp 4907-4918

Mase H, Kitano T, Morioka S (2000) Application of generalized Pareto distribution to extreme wave statistics. Proc Coast Eng JSCE 47:221-225 (in Japanese) 
Reis MT (1998) Probabilistic assessment of the safety of coastal structures. Ph.D. thesis, Department of Civil Engineering, University of Liverpool, Liverpool

Reis MT, Hedges TS, Williams A, Keating K (2006) Specifying seawall crest levels with the help of a probabilistic method. Maritime Eng J Proc ICE 159(4):137-145

Shore Protection Manual (1984) Coastal Engineering Research Center. US, Army Corps of Engineers, US

Takahashi S, Hanzawa M, Sato H, Gomyuo M, Shimosako K, Terauchi K, Takayama T, Tanimoto K (1998) Lifetime damage estimation with a new stability formula for concrete blocks. Report of the Port and Harbour Research Institute, vol 37, no. 1, pp 3-32

Technical Standards and Commentaries for Port and Harbour Facilities in Japan (2007) The Overseas Coastal Area Development Institute of Japan (OCDI), p 980
US Army Corps of Engineers (2002) Coastal engineering manual, EM 1110-2-1100. USACE, Washington, DC

Van der Meer JW (1987) Stability of breakwater armor layer design formulae. Coast Eng 11:219-239

Van der Meer JW (1988a) Rock slopes and gravel beaches under wave attack. Ph.D. thesis, Delft University of Technology, Delft

Van der Meer JW (1988b) Stability of cubes, tetrapods and accropode. In: Proceedings of the conference of breakwater'88, pp 71-80

Van Gent MRA, Smale AJ, Kuiper C (2003) Stability of rock slopes with shallow foreshores. In: Proceedings of the coastal structures 2003, Portland, Oregon, pp 100-112

Vidal C, Medina R, Lomonanco P (2006) Wave height parameter for damage description of rubble mound breakwater. Coast Eng 53(9):711-722 